\title{
Nanocrystallization in a Cu-doped Fe-based metallic glass
}

Y. Wu ${ }^{1,2,3}$, H. X. Li ${ }^{1}$, J. E. Gao ${ }^{1}$, H. Wang ${ }^{1}$, X. J. Liu ${ }^{1}$, M. K. Miller ${ }^{2}$, H. Bei ${ }^{2}$, Y. F. Gao ${ }^{3}$, Z. P. $\mathrm{Lu}^{1 *}$

${ }^{1}$ State Key Laboratory for Advanced Metals and Materials, University of Science and Technology Beijing, Beijing, 100083, China.

${ }^{2}$ Materials Science and Technology Division, Oak Ridge National Laboratory, Oak Ridge, TN 37831, USA.

${ }^{3}$ Materials Science and Engineering Department, University of Tennessee Knoxville, Knoxville, TN 37996, USA

\begin{abstract}
Evolution of microstructure and magnetic properties during annealing of a $\mathrm{Cu}$ doped $\mathrm{Fe}_{75.3} \mathrm{C}_{7.0} \mathrm{Si}_{3.3} \mathrm{~B}_{5.0} \mathrm{P}_{8.7} \mathrm{Cu}_{0.7}$ metallic glass were investigated via atom probe tomography. $\mathrm{Cu}$ segregation, which contains a rapid nucleation stage and a sluggish growth stage, was found to precede and may trigger the segregation of other elements and promote the following nanocrystallization. The nano-sized $\alpha$-Fe precipitates have a composition close to that of the grain-orientated high-silicon steel, giving rise to the enhancement in the magnetization.
\end{abstract}

Keywords: amorphous materials; clusters; nanostructures; magnetic measurements

*Corresponding author: luzp@ustb.edu.cn

(C) 2016. This manuscript version is made available under the Elsevier user license http://www.elsevier.com/open-access/userlicense/1.0/ 


\section{Introduction}

In recent years, Fe-based metallic glasses (MGs) have been widely utilized as high efficiency transformer materials due to their high permeability, low coercive force, and low core losses [1-6]. To further improve energy efficiency, two critical challenges regarding these glassy alloys, however, must be addressed urgently, i.e., the low glassforming ability (GFA) which results in low packing density (due to the adhesive needed to laminate the thin ribbons together) and increases Joule heat losses, and the relatively low magnetization $\left(\mathrm{M}_{\mathrm{s}}\right)$ as compared to that of grain-orientated high-silicon steels $[7,8]$. Recently, it was reported that with minor additions of the $\mathrm{Cu}$ element which has positive heat of mixing with Fe, both the GFA and soft magnetic and mechanical properties of Febased BMGs were dramatically enhanced [9-12]. Furthermore, an appropriate annealing below the glass transition temperature $\left(T_{g}\right)$ was verified to further improve the $M_{s}$ value of these $\mathrm{Cu}$-doped $\mathrm{Fe}$-based BMGs, whereas over-aging was found to deteriorate the soft magnetic properties [13-15]. As pointed out by Hono et al. [14, 15], $\mathrm{Cu}$ atomic clusters were present in the amorphous state after annealing below the crystallization temperature and gave rise to formation of a high density of tiny $\alpha$-Fe particles, which might be responsible for the $\mathrm{M}_{\mathrm{s}}$ enhancement [13-15]. Even though effects of $\mathrm{Cu}$ additions on heterogeneous nanocrystallization and dependence of magnetic properties on annealing conditions have been investigated in several Fe-based metallic glasses, limited studies regarding the entire dynamic crystallization process were conducted $[16,17]$, especially in those which have a complex atomic structure and nanocrystallization process [18]. Clearly, detailed evidences on evolution of local chemistry around the primary phases during de-vitrification are still missing[19]. As a result, the kinetics and elemental 
partitioning related to the transformation of the first $\mathrm{Cu}$ atomic clusters from an initial amorphous state into precipitates with an observable crystalline structure are far from being well understood [16]. This situation is due to the fact that the $\mathrm{Cu}$ clusters formed at the very early stages of clustering are very small in size with relatively a low volume fraction [17]. Visualizing them in three-dimensions is challenging [20], which results in difficulties in optimizing annealing treatment and processing conditions.

Atom probe tomography (APT) is capable of providing spatial coordinates and elemental identities of the atoms so that their distribution within small volumes of the specimen can be reconstructed in three-dimensions $[21,22]$. In recent years, APT has been widely used in the field of MGs to examine local atomic packing structure and elemental distribution [14-15]. In this study, the APT technique to investigate elemental redistribution during nanocrystallization process of a Fe-based $\mathrm{BMG}$ doped with $\mathrm{Cu}$, and attempted to reveal possible mechanisms responsible for the enhancement in the soft magnetic properties. These results will shed new insights into understanding alloying effects on the soft magnetic properties in general, and particularly those alloyed with the elements having positive heat of mixing with the main constituent.

\section{Experimental}

Alloy ingots with a nominal composition of $\mathrm{Fe}_{75.3} \mathrm{C}_{7.0} \mathrm{Si}_{3.3} \mathrm{~B}_{5.0} \mathrm{P}_{8.7} \mathrm{Cu}_{0.7}$ (at. \%) [13], hereafter designated as $\mathrm{Cu} 0.7$, were prepared by arc-melting a mixture of pure elements (99.9 \%) and the Fe-P alloys (P: 26.28, Si:0.01, C:0.02, Mn:0.69, Ti:0.35, Ca:0.01, S: $0.01 \mathrm{wt} \%$ ) under an argon atmosphere. Ribbon samples with a width of 1-2 $\mathrm{mm}$ and a 
thickness of $30-50 \mu \mathrm{m}$ were prepared by the melt-spinning technique. Glass transition temperature $T_{g}$ and onset crystallization temperature $T_{x}$ are 760 and $774 \mathrm{~K}$, respectively [13]. The as-spun ribbons were annealed at temperatures lower than $T_{g}$, i.e., 729 and 749 $\mathrm{K}$ for different times under vacuum. Structures of the as-spun and annealed ribbons were characterized by $\mathrm{x}$-ray diffraction $(\mathrm{XRD})$ with $\mathrm{Cu}-\mathrm{K} \alpha$ radiation. Saturation magnetization $\left(\mathrm{M}_{\mathrm{s}}\right)$ and coercive force $(\mathrm{Hc})$ were measured with a vibrating sample magnetometer (VSM) under an applied field of $800 \mathrm{kA} / \mathrm{m}$. Needle-shaped specimens for APT characterization were fabricated by a lift-out method in a FEI Nova ${ }^{\mathrm{TM}} 200$ Nanolab $^{\mathrm{TM}}$ focused ion beam (FIB) instrument $[14,15]$. The APT analyses were performed in a Cameca Instruments LEAP 4000X HR in either voltage or laser $(\lambda=400 \mathrm{~nm}, 100 \mathrm{kHz}$ pulse repetition rate) modes. The data were binned and the concentration isosurfaces were generated according to a standard method detailed in reference 16. A voxel size of $1 \times 1 \times 1 \mathrm{~nm}^{3}$ and a delocalization parameter $\mathrm{D}=2 \mathrm{~nm}$ were used to depict the elemental concentration isosurfaces. To eliminate possible effects from Ga damage during the sample preparation, only data of the inner part of the needle were chosen for analysis.

\section{Results and discussion}

X-ray diffraction (XRD) patterns of the as-spun and annealed Cu0.7 samples at $729 \mathrm{~K}$ and $749 \mathrm{~K}$ are shown in Fig. 1a. Both the as-spun and the specimen annealed at 729 $\mathrm{K}$ for 15 min show only a hump with no crystalline peaks, suggesting an amorphous structure without obvious crystalline phase. Nevertheless, the sample annealed for $30 \mathrm{~min}$ shows sharp peaks superposed on the hump, and these crystalline peaks were indexed as $\alpha-\mathrm{Fe}$, suggesting that this sample was partially crystallized. Magnetization curves of the 
as-spun and annealed samples are shown in Fig. $1 \mathrm{~b}$. The $\mathrm{M}_{\mathrm{s}}$ value of the as-cast sample is $1.61 \mathrm{~T}$. The $\mathrm{M}_{\mathrm{s}}$ value increased to 1.68 and $1.79 \mathrm{~T}$ for specimens annealed at $729 \mathrm{~K}$ for 15 and $30 \mathrm{~min}$, respectively. With the further increase of the annealing temperature to $749 \mathrm{~K}$ for $30 \mathrm{~min}$, the $\mathrm{M}_{\mathrm{s}}$ value decreased to $1.55 \mathrm{~T}$. The as-cast sample has a coercivity of 6.7 $\mathrm{A} / \mathrm{m}$ and slightly decreases when annealed at $729 \mathrm{~K}$ for $15 \mathrm{~min}$, whilst increases when the annealing time or/and temperature is increased (Fig. 1c). It can be seen that a proper annealing treatment appreciably enhanced $\mathrm{M}_{\mathrm{s}}$, whereas excessive annealing deteriorated both $\mathrm{M}_{\mathrm{s}}$ and $\mathrm{Hc}$ of this $\mathrm{Cu} 0.7$ glassy alloy. Therefore, it is necessary to investigate the structure evolution during annealing so that the underlying mechanism can be well understood.

Representative 3D reconstructions of the atomic positions of $\mathrm{Fe}, \mathrm{B}, \mathrm{C}, \mathrm{P}, \mathrm{Si}$ in the sample containing approximately 45 million atoms annealed at $729 \mathrm{~K}$ for $15 \mathrm{~min}$. is shown in Fig. 2a, and clearly shows a homogeneous distribution of these five elemental constituents throughout the sample. For the $\mathrm{Cu}$ atoms, however, the atom map in Fig. $2 \mathrm{a}$ and the corresponding 5\% iso-concentration surfaces, shown in Fig. 2b, indicated phase separation of $\mathrm{Cu}$. Note that this $5 \%$ threshold is much higher than the nominal composition of $0.7 \% \mathrm{Cu}$ and cannot be due to random local fluctuations of the $\mathrm{Cu}$ atoms. Therefore, numerous $\mathrm{Cu}$-enriched nano-precipitates have been formed in this stage. Based on the compositional line scanning across the amorphous matrix and the $\mathrm{Cu}-$ enriched nano-precipitates, shown in Fig. 2c, the nano-precipitates are enriched with up to $15 \% \mathrm{Cu}$ and consequentially contain lower amounts of the other elements. It has been reported that the well-grown $\mathrm{Cu}$ particles in Fe-based BMGs usually have a high $\mathrm{Cu}$ content near $100 \%$ due to the positive heat of mixing between $\mathrm{Cu}$ and $\mathrm{Fe}[23,24]$. It can 
thus be reasonably induced that diffusion and agglomeration of $\mathrm{Cu}$ atoms might be gradually taking place, but did not yet reach the fully-segregated equilibrium state at this early annealing stage of $15 \mathrm{~min}$.

As the annealing time was extended to $30 \mathrm{~min}$, elemental segregation occurred not only for $\mathrm{Cu}$, but also for all the other elements. Representative spatial distribution of $\mathrm{Fe}, \mathrm{C}$ and $\mathrm{Cu}$ atoms are shown in Fig. 3a-3c, respectively. The spatial distribution of $\mathrm{Fe}$, $\mathrm{C}$ or $\mathrm{Cu}$ is not uniform even at the atomic scale, and numerous nano-sized particles with elemental segregation can be observed, which is consistent with the TEM observation [13]. The nano-sized $\alpha$-Fe phase was found to be isolated by the amorphous matrix or/and small-sized iron-based compounds. With the increase of the nano-sized $\alpha$-Fe, saturation magnetization was enhanced [25-27]. Segregation process of $\mathrm{Cu}$ can be further studied from the evolution of the size and density of the $\mathrm{Cu}$ nano-precipitates during annealing. The size and number density of the $\mathrm{Cu}$ precipitates are listed in Table 1 . During the early annealing stage $(0-15 \mathrm{~min})$, the number density of the $\mathrm{Cu}$ precipitates burst into $1.6 \times 10^{24} \mathrm{~m}^{-3}$ with an average Guinier radius of $0.8 \pm 0.2 \mathrm{~nm}$. During the extended annealing stage, i.e., $30 \mathrm{~min}$, the number density of $\mathrm{Cu}$ precipitates decreased to $1.1 \times 10^{24}$ $\mathrm{m}^{-3}$, while the size of the $\mathrm{Cu}$ particles increased to $1.3 \pm 0.3 \mathrm{~nm}$, indicating occurrence of coarsening of the $\mathrm{Cu}$ precipitates by dissolution of some small $\mathrm{Cu}$ particles. Although $\mathrm{Cu}$ precipitation is the first to occur among the precipitation of all the constituent elements, the $\mathrm{Cu}$ precipitates have a slower growing rate during annealing compared with those of other precipitates.

When the sample was annealed at $749 \mathrm{~K}$ for $30 \mathrm{~min}$, significant devitrification and strong elemental fluctuation at tens of nanometers were observed (Fig. 4a). In 
addition to the amorphous matrix, an $\alpha$-Fe phase tens of nanometers in extent, ultrafine spheroidal $\mathrm{Cu}$-rich precipitates, and silicon-depleted $\mathrm{Fe}_{3}(\mathrm{P}, \mathrm{B}, \mathrm{C})$ and $\mathrm{Fe}_{3} \mathrm{C}$ phases were also observed under this annealing condition. The $\mathrm{Cu}$ precipitates are at the scale of several to tens of nanometer, which is slightly larger than that in the sample annealed at $729 \mathrm{~K}$ for $30 \mathrm{~min}$. Elemental concentration distribution across the interface between the $\mathrm{Cu}$ precipitates and the surrounding phases is shown in Fig. $4 \mathrm{~b}$. The $\mathrm{Cu}$ content is gradually increases from the interface and reaches near $100 \%$ in the center of $\mathrm{Cu}$ precipitates. The high copper level estimated from the compositional line scanning in the spheroidal $\mathrm{Cu}$ precipitates suggests that they are $\varepsilon$ - $\mathrm{Cu}$ with fcc structure, rather than bcc$\mathrm{Cu}$. The $\mathrm{Cu}$ concentration inside the $\mathrm{Cu}$ precipitates in this annealed sample (i.e., $30 \mathrm{~min}$. at $749 \mathrm{~K}$ ) was much higher than that in the sample annealed at $729 \mathrm{~K}$, implying that distinct elemental diffusion took place during the longer annealing process. Nevertheless, it is to be noted that even after annealing at a higher temperature for a longer time, the $\mathrm{Cu}$ precipitates were still at the length scale of less than $5 \mathrm{~nm}$. Therefore, evolution of $\mathrm{Cu}$ precipitates during annealing can be rationalized as a fast nucleation stage, followed by the slow growth and coarsening stages mediated by elemental redistribution at the nanometer scale. Clearly, phase separation consumes copper atoms in a very small volume around the $\mathrm{Cu}$ precipitate, whereas the growth of these precipitates requires the long-range diffusion of $\mathrm{Cu}$ in the surrounding media. Note that the elemental diffusion should first be in the metallic glassy matrix, but soon becomes transporting in crystallized phases.

In addition to the observed segregation of $\mathrm{Cu}$, distinct redistribution of the other constituent elements was also found during the long annealing. Elemental concentration 
distribution profile across the interface between $\alpha-\mathrm{Fe}$ and the surrounding crystals is shown in Fig. 4c. The isolated $\alpha$-Fe phase is significantly enriched in silicon and has a composition close to that of the grain-oriented silicon steel (i.e., $\mathrm{Fe}_{14} \mathrm{Si}_{2}$ ). No other solutes were present in a significant amount in the $\alpha$-Fe phase. Owing to its composition character and isolated nature, the nano-sized $\alpha$-Fe phase was believed to contribute to the enhanced $\mathrm{M}_{\mathrm{s}}$ value of the annealed samples. The Cu precipitates were also observed on the surface of the $\alpha$-Fe phase, implying that the precipitation of $\mathrm{Cu}$ during the early annealing stage may trigger the segregation of the other elements.

In addition, redistribution of the metalloid elements was also found to be highly inhomogeneous. As shown in Fig. 4a, the 3D elemental distribution map of the metalloids shows distinct segregation characteristics. Nano-sized $\mathrm{Fe}_{3} \mathrm{C}$ and $\mathrm{Fe}_{3}(\mathrm{P}, \mathrm{B}, \mathrm{C})$ can be clearly seen. Elemental concentration distribution profile across the interface between the $\mathrm{Fe}_{3} \mathrm{C}$ and $\mathrm{Fe}_{3}(\mathrm{P}, \mathrm{B}, \mathrm{C})$ phases is shown in Fig. 4d. The irregularly-shaped C-enriched phase, $\mathrm{Fe}_{3} \mathrm{C}$, is also enriched in $\mathrm{P}$ and $\mathrm{Si}$ and contains some B. The irregularly-shaped Penriched phase, $\mathrm{Fe}_{3}(\mathrm{P}, \mathrm{B}, \mathrm{C})$, is highly enriched in $\mathrm{B}$ but contains only a small amount of $\mathrm{C}$. Formation and growth of these iron-based compounds consumed part of $\alpha-\mathrm{Fe}$, which eventually deteriorates the soft magnetic properties of the current alloy.

From these analysis, it can be seen that the $\mathrm{Cu}$ clustering played an important role in nanocrystallization of the current Fe-based MG during annealing. To further study role of the minor additions of $\mathrm{Cu}$, the $7.5 \% \mathrm{P}$ iso-concentration surfaces and $3 \% \mathrm{Cu}$ isoconcentration surfaces for the sample annealed $30 \mathrm{~min}$. at $749 \mathrm{~K}$ were used to identify the positions of the $\mathrm{Cu}$ precipitates (Fig. 4e). Most spherical copper precipitates were located preferentially on the interfaces of other phases. A lower number density of intraphase $\mathrm{Cu}$ 
precipitates, i.e., the ones circled in Fig. 4e, were also observed, and they were slightly smaller.

These results indicate that after 15 min of annealing at $729 \mathrm{~K}$, only copper segregation is present in the amorphous matrix. Meantime, structural relaxation occurred during the early annealing, residual stress and defects such as free volume were reduced or annihilated, which would alleviate magnetic anisotropy and lead to increase of $\mathrm{M}_{\mathrm{s}}$ and decrease of $\mathrm{Hc}$ [27]. With the longer annealing time of $30 \mathrm{~min}$ at the same temperature, there were indications of phase separation of the other elements, particularly Fe and C. It seems that $M_{s}$ was increased due to formation of more $\alpha-F e$, but $H_{c}$ was also increased due to its increased grain size [27]. During annealing for $30 \mathrm{~min}$ at the higher temperature of $749 \mathrm{~K}$, the $\mathrm{Cu}$ precipitates were larger and present at lower number densities, and distinct $\alpha-\mathrm{Fe}, \mathrm{Fe}_{3} \mathrm{C}$ and $\mathrm{Fe}_{3}(\mathrm{P}, \mathrm{B}, \mathrm{C})$ phases were observed. By combining these results, the precipitation sequence appears to entail the initial phase separation of the $\mathrm{Cu}$ precipitates, and when their respective incubation periods were exceeded these $\mathrm{Cu}$ precipitates act as preferential nucleation sites for the $\alpha-\mathrm{Fe}, \mathrm{Fe}_{3} \mathrm{C}$ and $\mathrm{Fe}_{3}(\mathrm{P}, \mathrm{B}, \mathrm{C})$ phases. The $\mathrm{Cu}$ precipiates will also be pinning sites for their respective interfaces during growth of these ironcontaining phases. The isolated nano-sized $\alpha$-Fe precipitates had a composition close to the orientated silicon steel, which improved the magnetization. The increase in the size of the $\alpha$-Fe phase, and the formation of the other iron-based compounds containing the metalloid elements deteriorated the soft magnetic properties. It is important to point out that for actual applications of Fe-based BMGs as soft magnetic materials, both magnetization and coercivity have to be considered. Proper processes such as rapid 
annealing [17] for properly controlling precipitation and nanocrystallization are crucial for achieving desirable overall soft magnetic properties.

\section{Conclusions}

Nanocrystallization behavior of a Cu-doped iron-based MG during annealing was investigated by APT. $\mathrm{Cu}$ segregation was found to precede and may trigger the segregation of other elements. Evolution of the $\mathrm{Cu}$ nano-precipitates can be regarded as a process of fast nucleation at the early stage, followed by slow coarsening at the late stage. The $\alpha$-Fe phase had a composition close to that of the grain-orientated silicon steel and was isolated by the residual amorphous matrix and/or the other crystalline phases enriched in the metalloids, giving rising to the enhanced magnetization. With excessive annealing treatment, extensive precipitation and coarsening of iron-based compounds deteriorated the soft magnetic properties.

\section{Acknowledgements}

This research was supported by National Natural Science Foundation of China (Nos. 51531001, 51422101, 51371003 and 51271212), 111 Project (B07003), international S\&T Cooperation Program of China (2015DFG52600) and Program for Changjiang Scholars and Innovative Research Team in University (IRT_14R05), Fundamental Research Fund for the Central Universities (Nos. FRF-TP-15-004C1 and FRF-TP-14009C1). Y. W. was supported "the Top-Notch Young Talents Program of China", H. Li appreciates the financial support from Beijing Natural Science Foundation (No. 2142022) 
and Program for Excellent Talents in Beijing Municipality. Atom probe tomography (MKM) was supported through a user project supported by ORNL's Center for Nanophase Materials Sciences (CNMS), which is sponsored by the Scientific User Facilities Division, Office of Basic Energy Sciences, U.S. Department of Energy. 


\section{References}

[1] Y. Yoshizawa, S. Oguma, K. Yamauchi, New Fe-based soft magnetic alloys composed of ultrafine grain structure. J. Appl. Phys. 64 (1988) 6044.

[2] K. Takenaka, A. D. Setyawan, P. Sharma, N. Nishiyama, A. Makino, Industrialization of nanocrystalline $\mathrm{Fe}-\mathrm{Si}-\mathrm{B}-\mathrm{P}-\mathrm{Cu}$ alloys for high magnetic flux density cores. J. Mag. Mag. Mater. 401 (2016) 479-483.

[3] A. Makino, T. Kubota, C. T. Chang, M. Makabe, A. Inoue, Fe-metalloids bulk glassy alloys with high Fe content and high glass-forming ability. J. Mater. Res. 23 (2008) 1339.

[4] B. L. Shen, M. Akiba, A. Inoue, Excellent soft-ferromagnetic bulk glassy alloys with high saturation magnetization. Appl. Phys. Lett. 88 (2006) 131907.

[5] Y. Wu, X. D. Hui, Z. P. Lu, Z. Y. Liu, L. Liang, G. L. Chen, Effects of metalloid elements on the glass-forming ability of Fe-based alloys. J. Alloys Compd. 467 (2009) 187-190.

[6] A. Inoue, J.S. Gook, Fe-Based Ferromagnetic Glassy Alloys with Wide Supercooled Liquid Region. Mater. Trans. JIM 36 (1995) 1180-1183.

[7] D. V. Louzguine-Luzgin, A. Inoue, Chaper Three-Bulk Metallic Glasses: Formation, Structure, Properties, and Applications. Handbook of Mag. Mater. 21 (2013) 131-171.

[8] R. B. Schwarz, T. D. Shen, U. Harms, T. Lillo, Soft ferromagnetism in amorphous and nanocrystalline. alloys. J. Mag. Mag. Mater. 283 (2004) 223-230.

[9] H. X. Li, J. E. Gao, Y. Wu, Z. B. Jiao, D. Ma, A. D. Stoica, X. L. Wang, Y. Ren, M. K. Miller, Z. P. Lu, Enhancing glass-forming ability via frustration of nano-clustering in alloys with a high solvent content. Sci. Rep. 3 (2013) 1983.

[10] R. Li, M. Stoica, J. Eckert, Effect of minor $\mathrm{Cu}$ addition on phase evolution and magnetic properties of $\left\{\left[\left(\mathrm{Fe}_{0.5} \mathrm{Co}_{0.5}\right)_{0.75} \mathrm{Si}_{0.05} \mathrm{~B}_{0.20}\right]_{0.96} \mathrm{Nb}_{0.04}\right\}_{100-\mathrm{x}} \mathrm{Cu}_{\mathrm{x}}$ alloys. Phys.: Conf. Ser. 144 (2009) 012042. 
[11] L. T. Dou, H. S. Liu, L. Hou, L. Xue, W. M. Yang, Y. C. Zhao, C. T. Chang, B. L. Shen, Effects of $\mathrm{Cu}$ substitution for Fe on the glass-forming ability and soft magnetic properties for Fe-based bulk metallic glasses. J. Mag. Mag. Mater. 358-359 (2014) 23-26.

[12] Z. Z. Li, A. D. Wang, C. T. Chang, Y. G. Wang, B. S. Dong, S. X. Zhou, FeSiBPNbCu alloys with high glass-forming ability and good soft magnetic properties. Intermetallics 54 (2014) 225-231.

[13] J. E. Gao, H. X. Li, Z. B. Jiao, Y. Wu, Y. H. Chen, T. Yu, Z. P. Lu, Effects of nanocrystal formation on the soft magnetic properties of Fe-based bulk metallic glasses. Appl. Phys. Lett. 99 (2011) 052504.

[14] K. Hono, D. H. Ping, M. Ohnuma, H. Onodera, Cu clustering and Si partitioning in the early crystallization stage of an $\mathrm{Fe}_{73.5} \mathrm{Si}_{13.5} \mathrm{~B}_{9} \mathrm{Nb}_{3} \mathrm{Cu}_{1}$ amorphous alloy. Acta Mater. 47 (1999) 997 1006.

[15] M. Ohnuma, K. Hono, S. Linderoth, J. S. Pedersen, Y. Yoshizawa, H. Onodera, J. Smallangle neutron scattering and differential scanning calorimetry studies on the copper clustering stage of $\mathrm{Fe}-\mathrm{Si}-\mathrm{B}-\mathrm{Nb}-\mathrm{Cu}$ nanocrystalline alloys. Acta Mater. 48 (2000) 47834790.

[16] K. G. Pradeep, G. Herzer, D. Raabe, Atomic scale study of $\mathrm{Cu}$ clustering and pseudohomogeneous Fe-Si nanocrystallization in soft magnetic $\mathrm{FeSiNbB}(\mathrm{Cu})$ alloys. Ultramicroscopy 159 (2015) 285-291.

[17] K. G. Pradeep, G. Herzer, P. Choi, D. Raabe, Atom probe tomography study of ultrahigh nanocrystallization rates in $\mathrm{FeSiNbBCu}$ soft magnetic amorphous alloys on rapid annealing. Acta Mater. 68 (2014) 295-309.

[18] M. Stoica, P. Ramasamy, I. Kaban, S. Scudino, M. Nicoara, G. B. M. Vaughan, J. Wright, R. Kumar, J. Eckert, Structure evolution of soft magnetic (Fe36Co36B19.2Si4.8Nb4)100-xCux ( $x=0$ and 0.5) bulk glassy alloys. Acta Mater 95 (2015) 335-342.

[19] M. J. Duarte, A. Kostka, J. A. Jimenez, P. Choi, J. Klemm, D. Crespo, D. Raabe, F. U. 
Renner, Crystallization, phase evolution and corrosion of Fe-based metallic glasses: An atomic-scale structural and chemical characterization study. Acta Mater. 71 (2014) 20-30.

[20] A. Shariq, T. Al-Kassab, R. Kirchheim, Studying nearest neighbor correlations by atom probe tompography (APT) in metallic glasses as exemplified for Fe40Ni40B20 glassy ribbons. J. alloys Compd. 512 (2012) 270-277.

[21] M. K. Miller and R. G. Forbes, Atom Probe Tomography: The Local Electrode Atom Probe, Springer, New York (2014).

[22] M. K. Miller, K. F. Russell, K. Thompson, R. Alvis, D. J. Larson. Review of atom probe FIB-based specimen preparation methods. Microscopy and Microanalysis. 13 (2007) 428436.

[23] A. Takeuchi, A. Inoue, Classification of Bulk Metallic Glasses by Atomic Size Difference, Heat of Mixing and Period of Constituent Elements and Its Application to Characterization of the Main Alloying Element. Mater. Trans, JIM 46 (2005) 2817-2829.

[24] X. Li, H. Kato, K. Yubuta, A. Makino, A. Inoue, Improved plasticity of iron-based highstrength bulk metallic glasses by copper-induced nanocrystallization. J. Non-Cryst. Solids 357 (2011) 3002-3005.

[25] G. Herzer, in: K.H.J. Buschow (Ed.), Handbook of Magnetic Materials, vol. 10, Elsevier, Amsterdam, 1997.

[26] K. Pekala, J. Latuch, T. Kulik, J. Antonowicz, P. Jaskiewicz, Magnetic and transport properties of nanocrystallizing supercooled amorphous alloy $\mathrm{Fe}_{74} \mathrm{Al}_{4} \mathrm{Ga}_{2} \mathrm{P}_{11} \mathrm{~B}_{4} \mathrm{Si}_{4} \mathrm{Cu}_{1}$. Mater. Sci. Eng. A 375-377 (2004) 377-380.

[27] G. Herzer, On the theoretical understanding of nanocrystalline soft magnetic materials. J. Mater. Eng. \& Perfor. 2 (1993) 193-198. 


\section{Captions}

Table 1 Number density and radius of the $\mathrm{Cu}$ precipitates in the as-cast and annealed samples.

Fig. 1 X-ray diffraction patterns (a) and Magnetization curves (b) of the Cu0.7 samples annealed at different temperature, and (c) variation of Ms and $\mathrm{Hc}$ of the Cu0.7 alloy as a function of annealing temperature.

Fig. 2 Elemental distribution of the sample annealed $15 \mathrm{~min}$ at $729 \mathrm{~K}$; (a) the elements $\mathrm{Fe}$, $\mathrm{Si}, \mathrm{B}, \mathrm{C}, \mathrm{P}$ and $\mathrm{Cu}$, and (b) iso-concentration surface of $5 \% \mathrm{Cu}$. (c) Compositional line scanning across the matrix and the $\mathrm{Cu}$-enriched nanoprecipiates. Length unit in the figures is $\mathrm{nm}$.

Fig. 3 Elemental distribution for the sample annealed at $729 \mathrm{~K}$ for $30 \mathrm{~min}, \mathrm{Fe}(\mathrm{a}), \mathrm{C}$ (b), and $\mathrm{Cu}(\mathrm{c})$. Length unit in the figures is $\mathrm{nm}$.

Fig. 4 3D reconstruction of elemental distribution for the specimens annealed at $749 \mathrm{~K}$ for $30 \mathrm{~min}(\mathrm{a})$, the compositional line scanning across the interface between the matrix and $\mathrm{Cu}$ particles (b), and the $\alpha-\mathrm{Fe}$ particles (c), compositional line scanning across the interface between $\mathrm{Fe}_{3} \mathrm{C}$ and $\mathrm{Fe}_{3}(\mathrm{P}, \mathrm{B}, \mathrm{C})(\mathrm{d})$, and (e) the $7.5 \% \mathrm{P}$ iso-concentration surface along with the $3 \% \mathrm{Cu}$ iso-concentration surface to show the location of $\mathrm{Cu}$ precipitates. 
Table 1

\begin{tabular}{lll}
\hline Treatment & Number density & Guinier Radius \\
\hline As cast & 0 & $\mathrm{n} / \mathrm{a}$ \\
$15 \mathrm{~min} @ 729 \mathrm{~K}$ & $1.6 \times 10^{24} \mathrm{~m}^{-3}$ & $0.8 \pm 0.2 \mathrm{~nm}$ \\
$30 \mathrm{~min} @ 729 \mathrm{~K}$ & $1.1 \times 10^{24} \mathrm{~m}^{-3}$ & $1.3 \pm 0.3 \mathrm{~nm}$ \\
\hline
\end{tabular}


Fig. 1

(a)

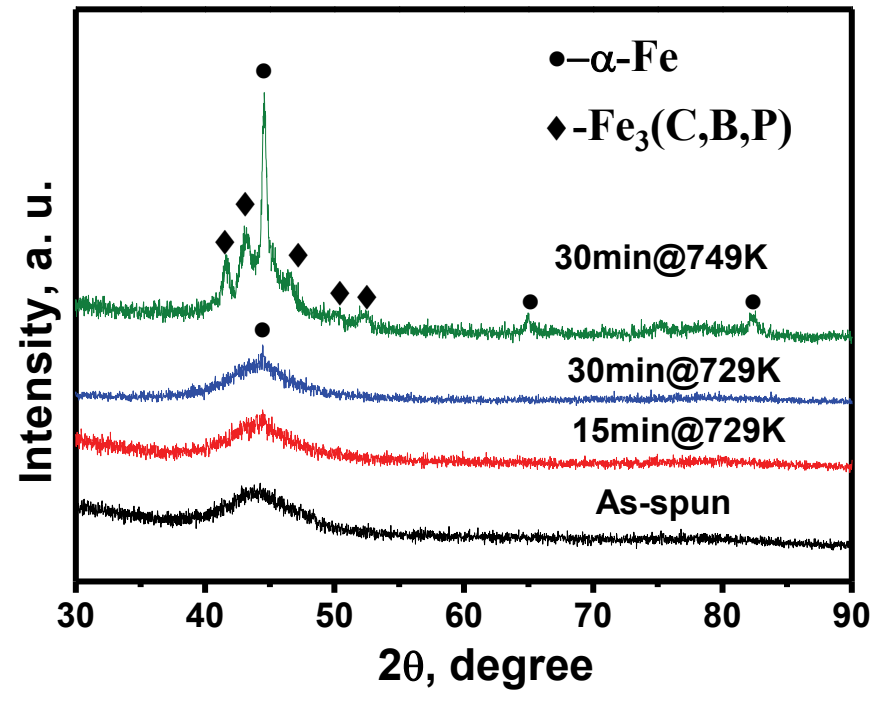

(b)

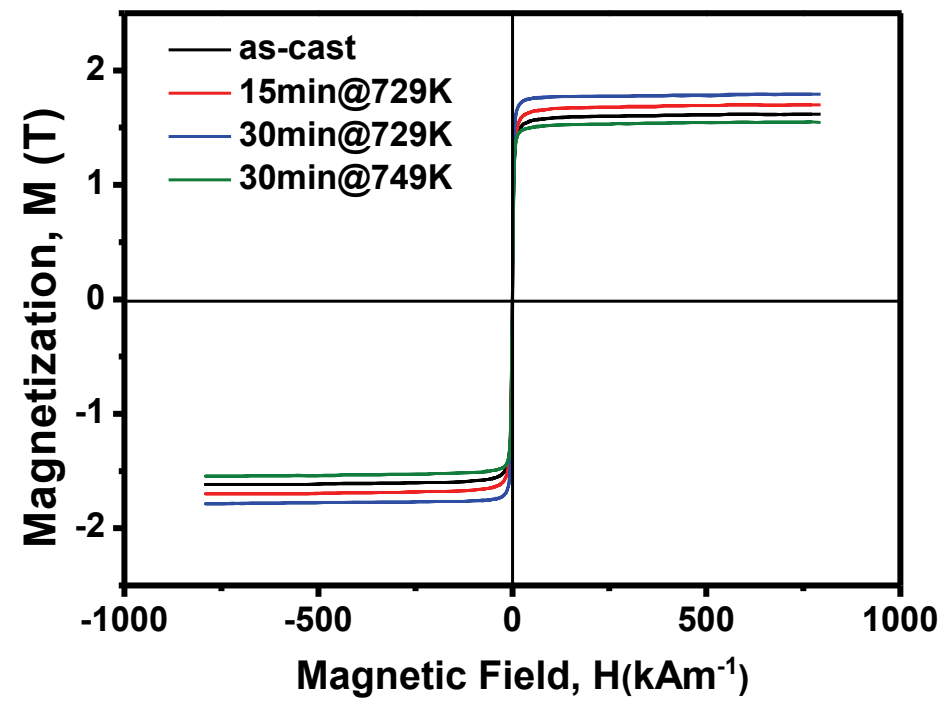


(c)

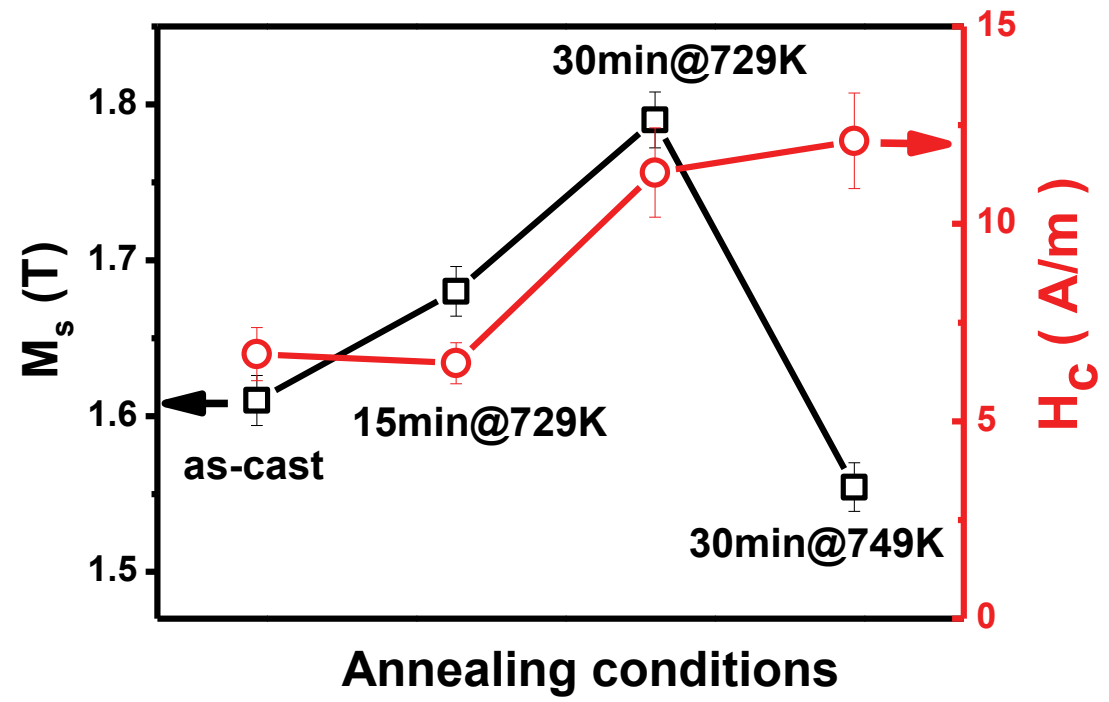


Fig. 2

(a)

Fe

C

B
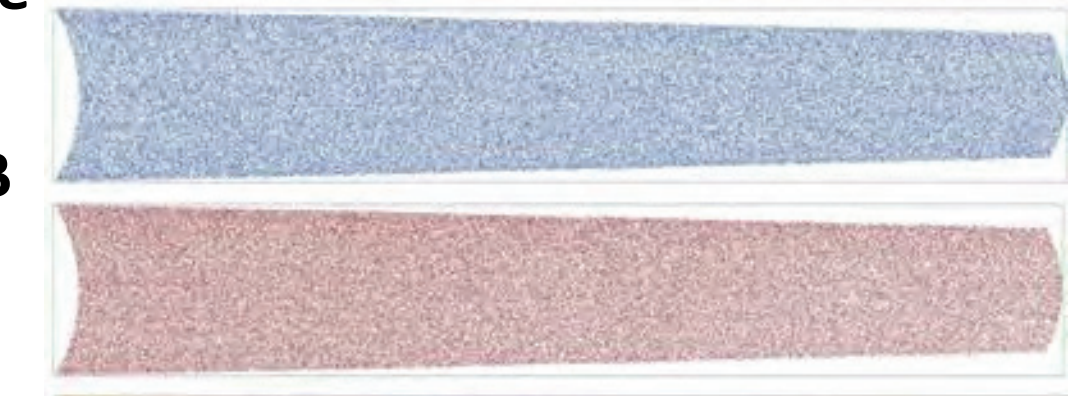

Si

$\mathrm{Cu}$ and in
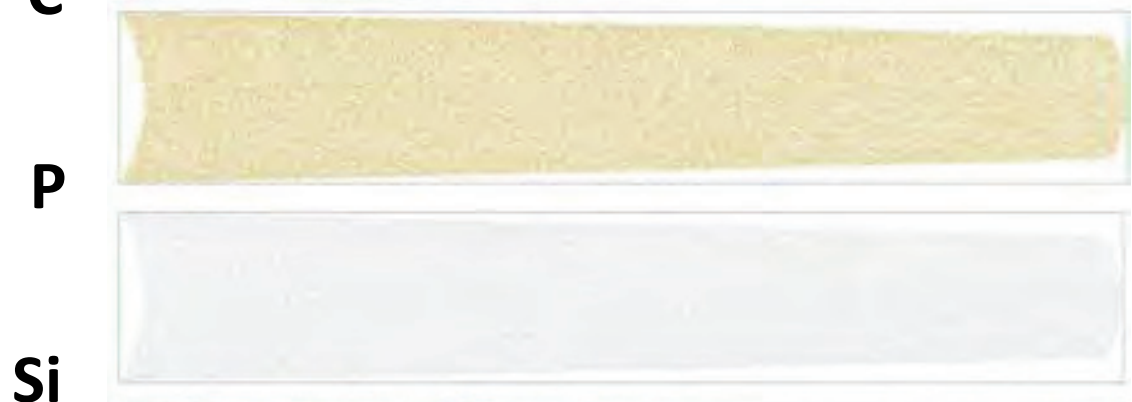

$20 \mathrm{~nm}$

(b)

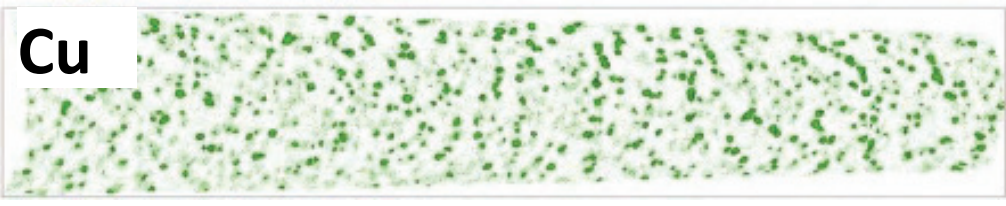

$20 \mathrm{~nm}$ 
(c)

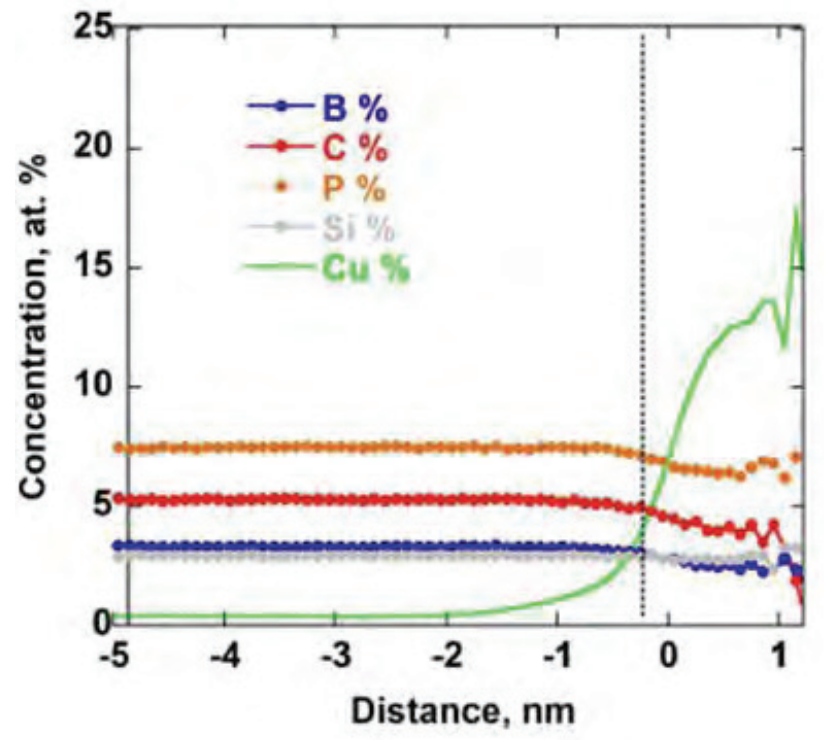


Fig. 3

(a)

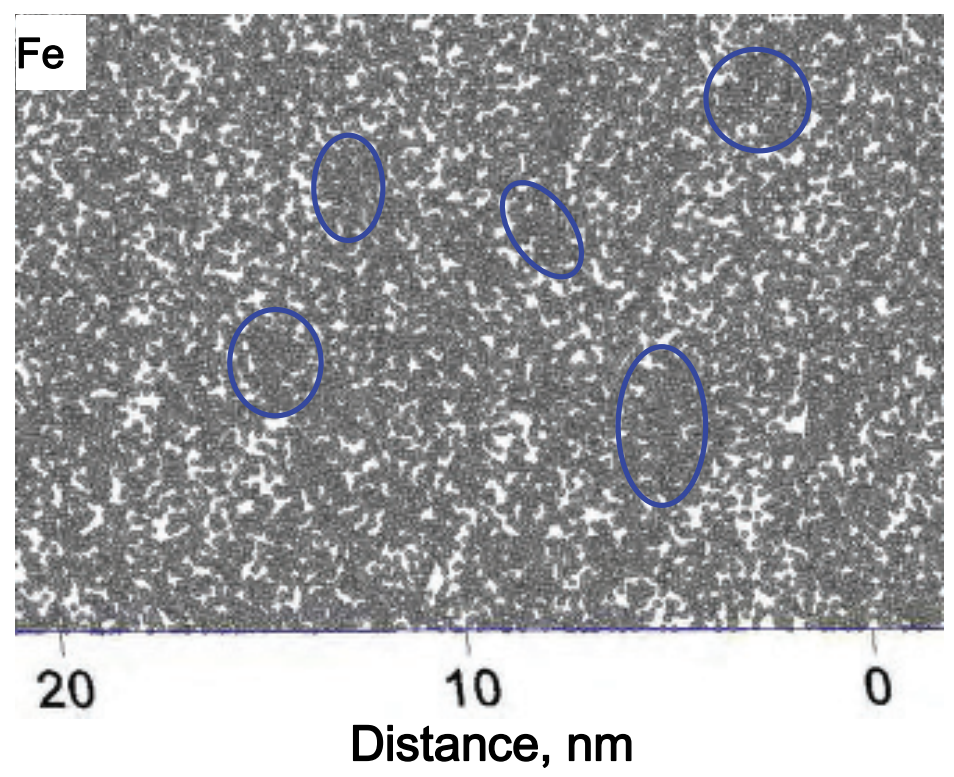

(b)

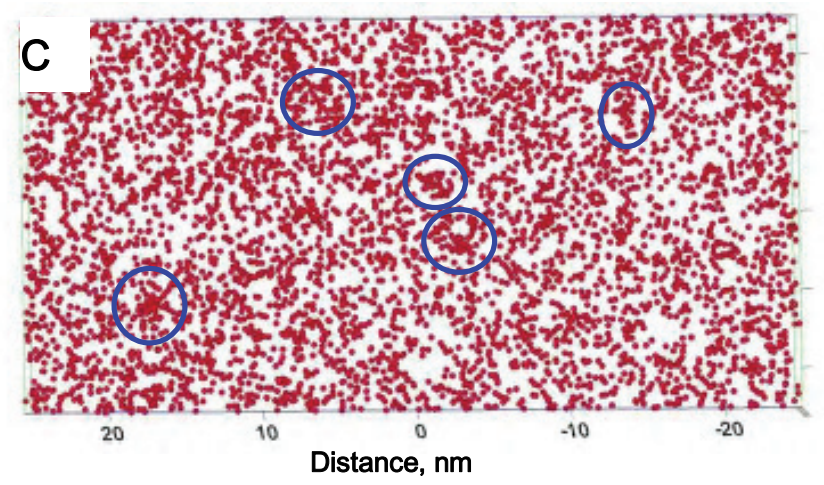

(c)

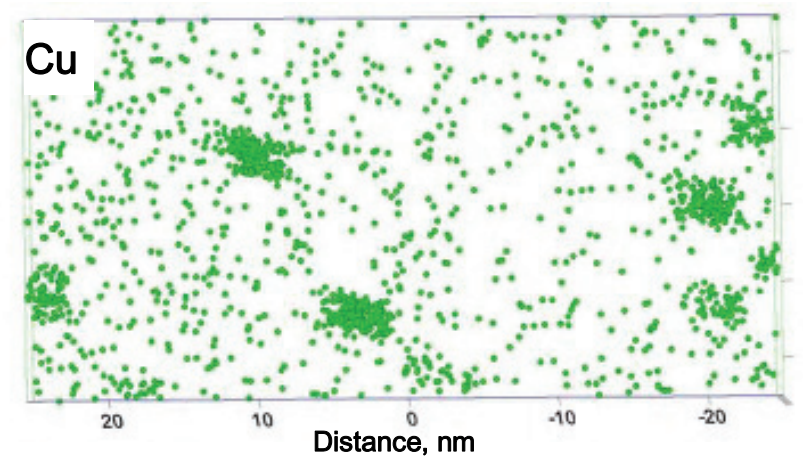


Fig. 4

(a)

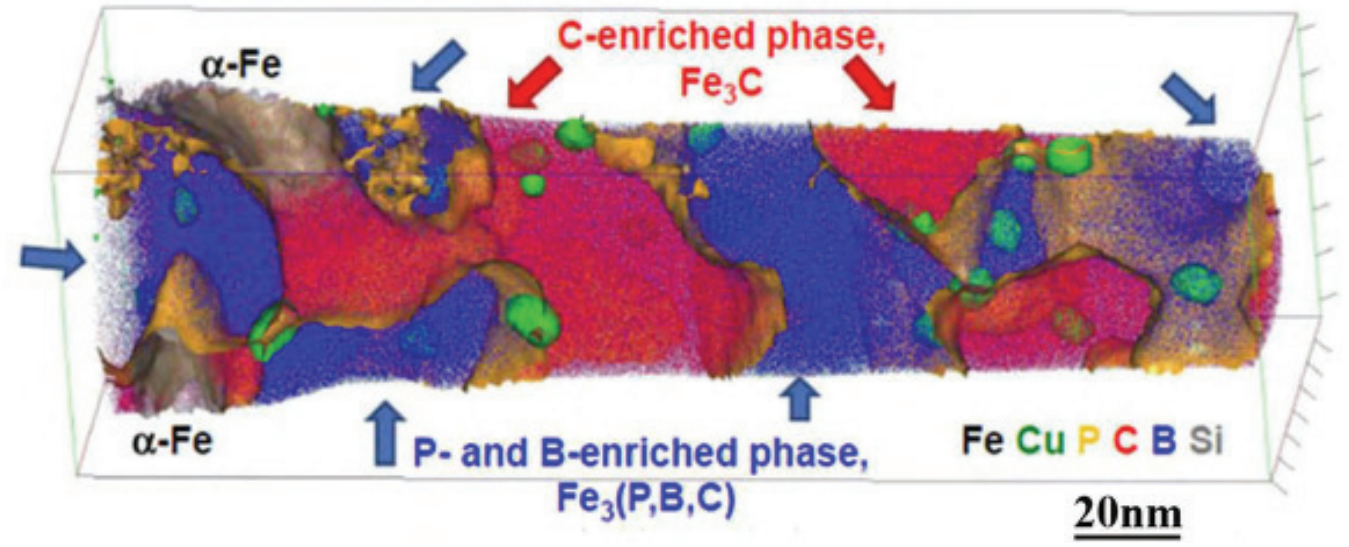

(b)

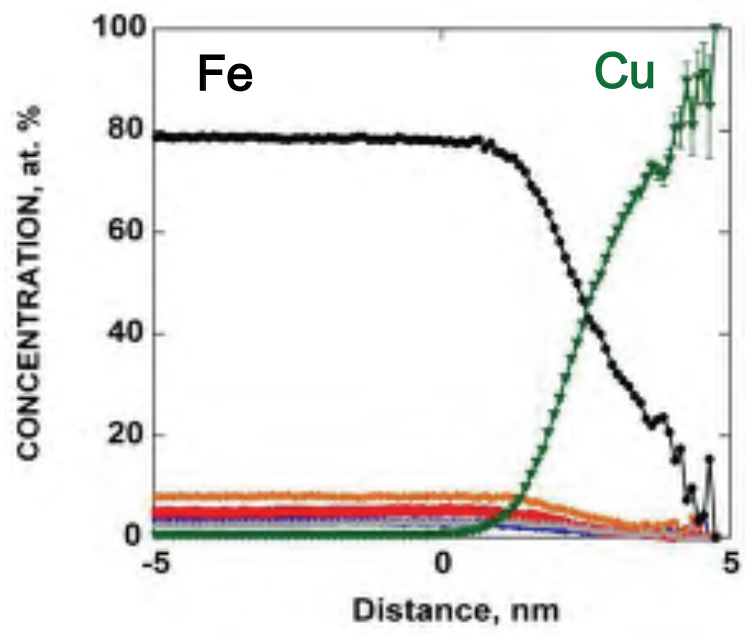


(c)

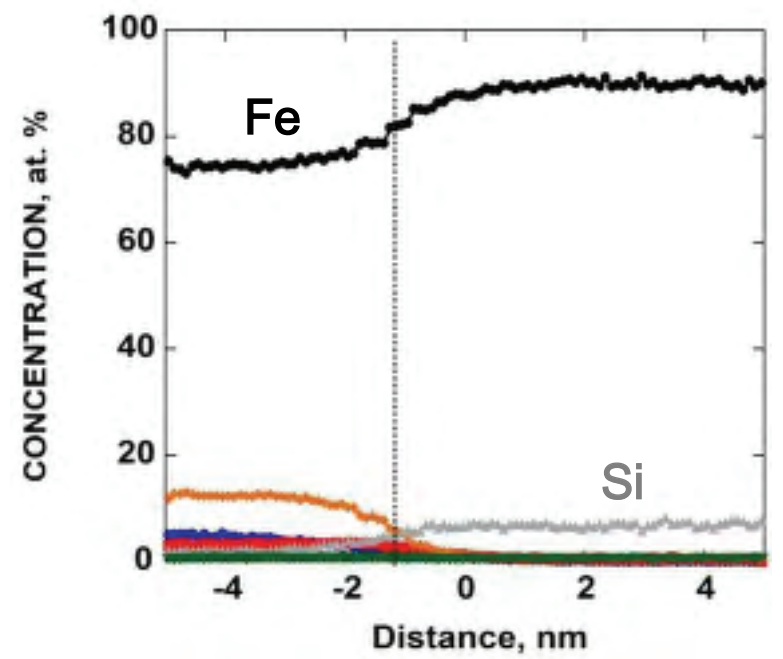

(d)

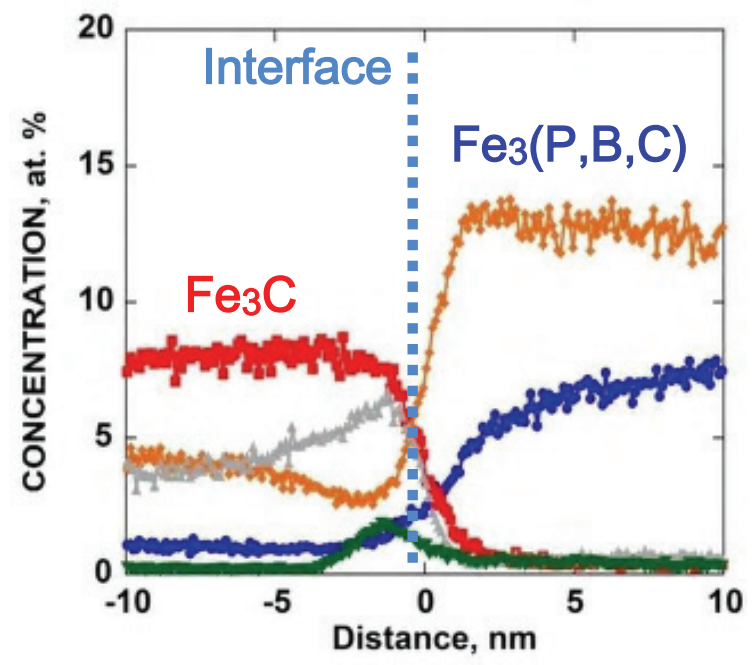


(e)

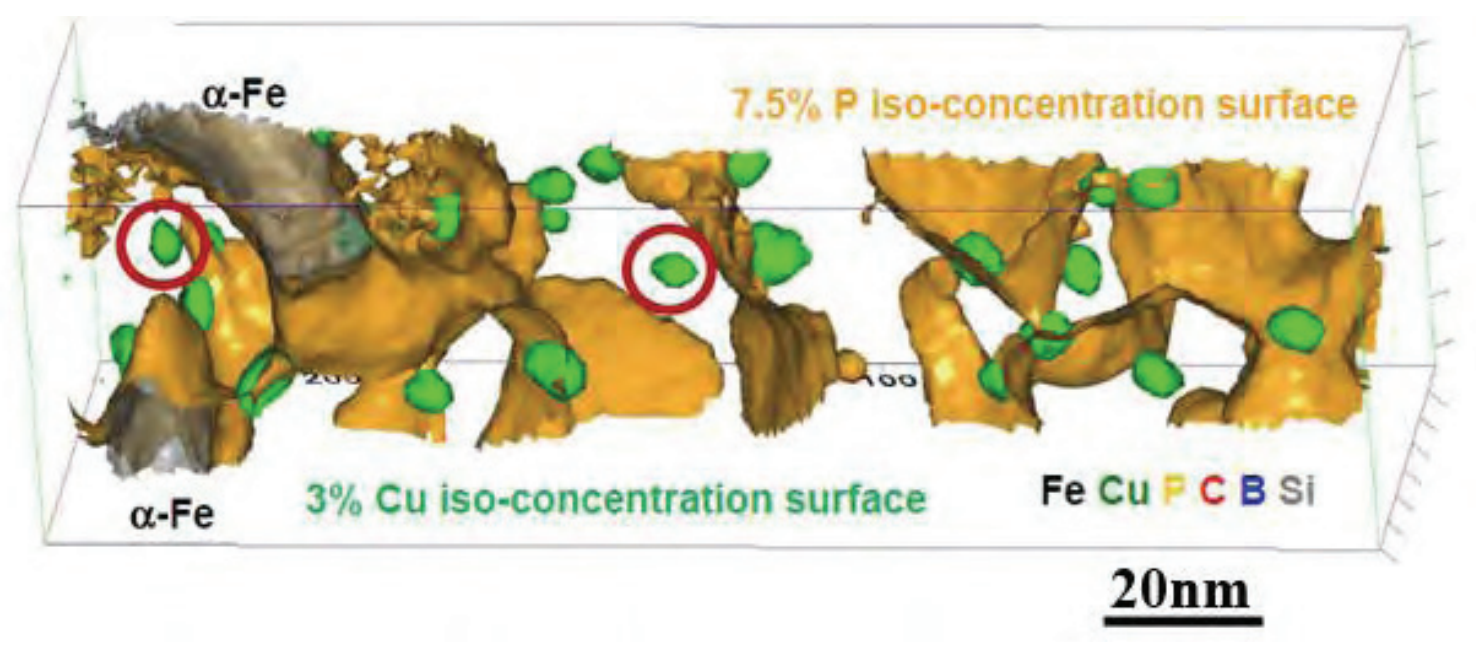

